\title{
FORMULATION AND EVALUATION OF ANTIMICROBIAL OINTMENTS FROM EUPATORIUM GLANDULOSUM HORT. EX KUNTH
}

\author{
SILPA M, SURESH JOGHEE*, HAMSALAKSHMI \\ Department of Pharmacognosy, JSS College of Pharmacy, JSS Academy of Higher Education \& Research, Mysuru, Karnataka, India. \\ Email: jsuresh@jssuni.edu.in
}

Received: 05 September 2018, Revised and Accepted: 13 November 2019

\begin{abstract}
Objective: The present study was undertaken to evaluate the antimicrobial activity of an ointment prepared from alcohol, ethyl acetate, and chloroform extracts of Eupatorium glandulosum Hort. ex Kunth.

Methods: The dried plant materials of E. glandulosum were individually extracted using alcohol, ethyl acetate, and chloroform by Soxhlet method. These three different types of extracts were used for the preparation of ointment and evaluated for the phytochemicals, $\mathrm{pH}$, homogeneity, spreadability, tube extrudability, stability, and antimicrobial activity. The activity of prepared ointments was evaluated against Escherichia coli and Bacillus subtilis and the in vitro antimicrobial activity of ointments of plant extracts was performed by cup plate methods. The most effective antimicrobial ointment was determined by comparing the results of the zone of inhibition of all the ointments of each solvent extract.
\end{abstract}

Results: The antimicrobial activity of optimized formulation was showed significant activity against the tested bacterial pathogens.

Conclusion: The present study confirmed the antimicrobial activity of the formulations. Furthermore, it can use as a potential dosage form for clinical utility. The results are the justification for the use of the plant in folk medicine.

Keywords: Eupatorium glandulosum, Herbal ointment, Cup plate method, Stability.

(C) 2020 The Authors. Published by Innovare Academic Sciences Pvt Ltd. This is an open access article under the CC BY license (http://creativecommons. org/licenses/by/4. 0/) DOI: http://dx.doi.org/10.22159/ajpcr.2020.v13i1.29533

\section{INTRODUCTION}

The bacterial infections mainly occur with the injuries or ulcers or after the surgical treatments. Antibacterial substances help to inhibit or kill bacterial cells [1]. Infectious diseases are an increasingly greater extent in recent years. Furthermore, antibiotic-resistant becomes a major therapeutic problem [2]. The infectious diseases killing 50,000 people every day, and now, this is a world-leading cause for premature death [3]. Natural products of higher plants may possess a new source of an antimicrobial agent with a possible novel mechanism of action [4,5]. The researchers reported the antimicrobial activity of many plants and secondary metabolites of plants such as alkaloids, tannins, terpenoids, and flavonoids mainly responsible for these activities [6].

Medicinal plants used for the antimicrobial treatment started in ancient times. Several medicinal plant extracts and its phytochemicals have shown activity against all types of microorganisms including both Gram-negative and Gram-positive bacteria [7].

Ointments are semisolid preparation. They may or may not be containing medication used for the external application. Medicated ointments are intended to be applied externally in the body or to the mucous membrane. Non-medicated ointments commonly used as a base for the preparation of medicated ointments or used as such for lubricating or emollient effects. Plant drugs can also be formulated in the form of ointment [8,9]. The effective ratio of active ingredients incorporating with ointment base by trituration and after completion of the formulation, the ointment quality is assessing in terms of diffusion, irritancy, stability, and spreadability [10].

Eupatorium glandulosum popularly known as cat weed, Nilgiri weed, goat weed, or Mexican devil belongs to the family Asteraceae. E. glandulosum grows up to 1-3 $\mathrm{m}$ in height and it as an erect herb or occasionally it may be a shrub [11]. A simple, opposite, glabrous, decussate, and deltoid-ovate-shaped leaves with purple underneath and it grows $10 \mathrm{~cm}$ in length. Flowers are white [12]. Tribal people of Nilgiris used the leaves paste to treat cuts and wounds [13].

E. glandulosum is rarely used for the studies and till now the plant not yet explored, consider the medicinal properties, it can be well used for commercial product.

\section{METHODS}

The aerial parts of E. glandulosum Hort. ex Kunth were freshly collected from Ooty (Nilgiri hills), Tamil Nadu, India, in August 2017. The plant was identified and authenticated by Dr. M N Naganandini, Department of Pharmacognosy, JSS College of Pharmacy, Mysuru, India. Further, the plant material was washed under tap water and dried under shade, coarsely powdered using a mechanical grinder, then passed through 40 meshes and stored in a well airtight container till further use.

\section{Method of extraction}

The coarsely powdered E. glandulosum was extracted separately with alcohol, ethyl acetate, and chloroform using Soxhlet apparatus. The extract was collected, concentrated under reduced pressure, stored in an airtight container, and kept in desiccator for further use.

\section{Preparation of herbal ointment}

Specific quantities of all the ingredients such as plant extracts, stearic acid, white wax, yellow paraffin, triethanolamine, methylparaben, propylparaben, and water were taken for the preparation. The bases were melted together at $70^{\circ} \mathrm{C}$ in a basal. After that, all the ingredients were stirred gently and maintained the same temperature for a certain period, then cooled with continuous stirring. Different proportions of extracts were incorporated into the base by trituration using mortar 
and pestle. The prepared ointments filled into the tube and stored at room temperature [14-16]. The formulation from different solvent extracts of E. glandulosum is tabulated in Tables 1-3.

\section{Evaluation of ointments}

Organoleptic parameters such as color, odor, and texture were inspected through visual inspection.

\section{Determination of $\mathrm{pH}$}

Pre-calibrated digital $\mathrm{pH}$ used for the determination of $\mathrm{pH}$ of ointments. One gram of ointment dissolved in distilled water $(100 \mathrm{ml})$ and keeps it aside for $2 \mathrm{~h}$. Standardization of the $\mathrm{pH}$ meter done with possible buffer solutions. Measurement of each sample solution done triplicate. The average values calculated and noted [17-19]

\section{Spreadability}

The spreadability of formulations determined using apparatus consists of a wooden block having a pulley at one end with a fixed glass slide on the block. Around $3 \mathrm{~g}$ of ointment placed on the ground plate and in between these plates and another glass plate having the same dimension of the fixed ground plate, the ointment sandwiched. On the top of these two plates, $1 \mathrm{~kg}$ weight placed for $5 \mathrm{~min}$ to expel air and to provide uniform of the ointment between the plates. The excess of

Table 1: Composition of ethyl acetate extracts ointment

\begin{tabular}{llllll}
\hline Ingredients & FEA1 & FEA2 & FEA3 & FEA4 & FEA5 \\
\hline Drugs (g) & 1.5 & 2.0 & 2.5 & 4.0 & 5.0 \\
Stearic acid (g) & 8 & 8 & 8 & 8 & 8 \\
White wax (g) & 4 & 4 & 4 & 4 & 4 \\
Yellow paraffin (g) & 16 & 16 & 16 & 16 & 16 \\
Triethanolamine (g) & 1 & 1 & 1 & 1 & 1 \\
Methyl paraben (g) & 0.2 & 0.2 & 0.2 & 0.2 & 0.2 \\
Propyl paraben (g) & 0.1 & 0.1 & 0.1 & 0.1 & 0.1 \\
Water (ml) & qs & qs & qs & qs & qs \\
\hline
\end{tabular}

FEA: Formulation of ethyl acetate

Table 2: Composition of alcoholic extracts ointment

\begin{tabular}{llllll}
\hline Ingredients & FA1 & FA2 & FA3 & FA4 & FA5 \\
\hline Drugs (g) & 1.5 & 2.0 & 2.5 & 4.0 & 5.0 \\
Stearic acid (g) & 8 & 8 & 8 & 8 & 8 \\
White wax (g) & 4 & 4 & 4 & 4 & 4 \\
Yellow paraffin (g) & 16 & 16 & 16 & 16 & 16 \\
Triethanolamine (g) & 1 & 1 & 1 & 1 & 1 \\
Methyl paraben (g) & 0.2 & 0.2 & 0.2 & 0.2 & 0.2 \\
Propyl paraben (g) & 0.1 & 0.1 & 0.1 & 0.1 & 0.1 \\
Water (ml) & qs & qs & qs & qs & qs \\
\hline
\end{tabular}

FA: Formulation of alcohol

Table 3: Composition of chloroform extracts ointment

\begin{tabular}{llllll}
\hline Ingredients & FC1 & FC2 & FC3 & FC4 & FC5 \\
\hline Drugs (g) & 1.5 & 2.0 & 2.5 & 4.0 & 5.0 \\
Stearic acid (g) & 8 & 8 & 8 & 8 & 8 \\
White wax (g) & 4 & 4 & 4 & 4 & 4 \\
Yellow paraffin (g) & 16 & 16 & 16 & 16 & 16 \\
Triethanolamine (g) & 1 & 1 & 1 & 1 & 1 \\
Methyl paraben (g) & 0.2 & 0.2 & 0.2 & 0.2 & 0.2 \\
Propyl paraben (g) & 0.1 & 0.1 & 0.1 & 0.1 & 0.1 \\
Water (ml) & qs & qs & qs & qs & qs \\
\hline
\end{tabular}

FC: Formulation of chloroform ointments scrapped off from the edges. Two hundred and forty grams pull off with top plate and time required by the top plate to cover a distance of $10 \mathrm{~cm}$ noted. The spread capacity expressed in terms of times in seconds taken by two slides to slip off from ointment placed in between the slides under the direction of a certain load [17,20-22]. The spreadability determined using the equation,

$$
\mathrm{S}=\mathrm{m} \times \mathrm{l} \div \mathrm{t}
$$

Where,

S - Spreadability

$\mathrm{m}$ - Weight tied to the upper slide

1 - Length of glass slides

$\mathrm{t}$ - Time is taken to separate the slide.

Separately measured the spreadability of each ointment and repeat 3 times for getting exact values and the average was taken as a consideration.

\section{Viscosity}

The viscosity of the formulation was done using Brookfield viscometer The test sample is taken into a dry and clean $250 \mathrm{ml}$ of the beaker. The viscosity of the sample determined at $25^{\circ} \mathrm{C}$ using viscometer. The viscosity measured in cps $[18,23]$

\section{Homogeneity}

Based on their appearance, all the developed ointments were tested for homogeneity by visual inspection [18]

\section{Tube extrudability}

It is a common test to obtain the force required to extrude the substance from the tube. The method applied for finding the applied shear in the region of rheogram corresponding to a shear rate exceeding the yield value and exhibiting consequent plug flow. In the present study, the method used for evaluating ointment formulation for extrudability based on the quantity in percentage ointment and extruded the ointment from the tube on a single application of pressure. More quantity of ointment extruded considered a better extrudability. The clean lacquered aluminum collapsible tube used to fill the ointment and the tube has a nozzle tip of $5 \mathrm{~mm}$ opening and applied the pressure on the tube with the help of a finger. It depends on the amount of ointment extruded from the tip when an external pressure applied on the tube is considered for the determination of the tube extrudability $[17,18]$.

\section{Antimicrobial studies}

Bacillus subtilis and Escherichia coli used for the determination of the antimicrobial activity of various ointment formulations and standard cup plate methods used for the study. The nutrient agar solution poured into the previously sterilized Petri dishes up to $5 \mathrm{~mm}$ thickness. Each microorganism added to Petri dishes with a sterilized loop and plates were allowed to solidify for $5 \mathrm{~min}$. On each Petri dish, five perforations made with a metal tube with a $4 \mathrm{~mm}$ diameter to receive test materials. The standard (neomycin sulfate ointment) and test materials (prepared formulations) added immediately into the wells and kept for incubation at $37^{\circ} \mathrm{C}$ for $24 \mathrm{~h}$ to allow the microorganism to grow and reagents to diffuse through the culture medium. At the end of the incubation, the zone diameter measured with the help of a zone reader $[17,24,25]$. All the experiments repeated 3 times to get accurate results.

\section{Stability studies}

In different temperature conditions, the stability studies carried out for all formulations $\left(4^{\circ} \mathrm{C}, 25^{\circ} \mathrm{C}\right.$, and $\left.37^{\circ} \mathrm{C}\right)$ for 3 months. All the evaluation parameters viscosity, $\mathrm{pH}$, consistency, spreadability, and phase

Table 4: Percentage yield of extracts

\begin{tabular}{llll}
\hline Type of extract & Alcoholic (\%) w/w & Ethyl acetate (\%) w/w & Chloroform (\%) w/w \\
\hline Yield of extract & 19.32 & 10.85 & 7.24 \\
\hline
\end{tabular}


Table 5: Evaluation of ointments

\begin{tabular}{|c|c|c|c|c|c|c|}
\hline Formulations & Appearance & Homogeneity & Spreadability in $1 \mathrm{~min}(\mathrm{~g})+\mathrm{SD}^{*}$ & $\begin{array}{l}\text { Viscosity } \\
\text { (cps)+SD* }\end{array}$ & $\mathrm{pH}+\mathrm{SD}^{*}$ & $\begin{array}{l}\text { Tube extrudability } \\
(\mathrm{g})=\mathrm{SD}^{*}\end{array}$ \\
\hline FEA1 & Greenish-brown & Good & $4.4 \pm 0.28$ & 5898 & $6.10 \pm 0.55$ & $0.69 \pm 0.35$ \\
\hline FEA2 & Greenish-brown & Good & $4.7 \pm 0.31$ & 6200 & $6.65 \pm 0.45$ & $1.4 \pm 0.28$ \\
\hline FEA3 & Brown & Good & $5.0 \pm 0.19$ & 5725 & $6.83 \pm 0.56$ & $1.30 \pm 0.32$ \\
\hline FEA4 & Dark brown & Good & $5.1 \pm 0.58$ & 6133 & $7.10 \pm 0.49$ & $0.85 \pm 0.19$ \\
\hline FEA5 & Dark brown & Good & $4.8 \pm 0.26$ & 5914 & $6.96 \pm 0.42$ & $0.91 \pm 0.61$ \\
\hline FA1 & Greenish-brown & Good & $4.2 \pm 0.41$ & 6157 & $6.26 \pm 0.41$ & $1.70 \pm 0.51$ \\
\hline FA3 & Greenish-brown & Good & $4.5 \pm 0.28$ & 5689 & $6.67 \pm 0.86$ & $0.82 \pm 0.42$ \\
\hline FA4 & Brown & Good & $4.8 \pm 0.54$ & 6183 & $7.00 \pm 0.62$ & $0.64 \pm 0.12$ \\
\hline FA5 & Dark brown & Good & $5.0 \pm 0.18$ & 6458 & $6.92 \pm 0.35$ & $0.78 \pm 0.57$ \\
\hline FC1 & Greenish-brown & Good & $4.2 \pm 0.62$ & 5421 & $6.59 \pm 0.33$ & $1.20 \pm 0.35$ \\
\hline $\mathrm{FC} 2$ & Greenish-brown & Good & $4.9 \pm 0.34$ & 5800 & $6.62 \pm 0.54$ & $0.69 \pm 0.24$ \\
\hline FC3 & Brown & Good & $4.4 \pm 0.32$ & 6400 & $6.70 \pm 0.23$ & $0.79 \pm 0.19$ \\
\hline FC4 & Brown & Good & $5.1 \pm 0.33$ & 5715 & $6.79 \pm 0.29$ & $0.98 \pm 0.35$ \\
\hline FC5 & Dark brown & Good & $5.0 \pm 0.21$ & 6521 & $6.96 \pm 0.48$ & $1.10 \pm 0.54$ \\
\hline
\end{tabular}

Table 6: Antimicrobial study

\begin{tabular}{llll}
\hline S. no. & Formulations & Zone of inhibition for Escherichia coli $(\mathbf{m m})$ SD $^{*}$ & Zone of inhibition for Bacillus subtilis (mm) SD* \\
\hline 1. & FEA1 & $12.60 \pm 0.18$ & $10.20 \pm 0.41$ \\
2. & FEA2 & $14.70 \pm 0.15$ & $18.50 \pm 0.52$ \\
3. & FEA3 & $12.00 \pm 0.17$ & $11.50 \pm 0.24$ \\
4. & FEA4 & $13.80 \pm 0.12$ & $19.80 \pm 0.17$ \\
5. & FEA5 & $18.50 \pm 0.17$ & $16.50 \pm 0.15$ \\
6. & FA1 & $19.31 \pm 0.12$ & $19.25 \pm 0.21$ \\
7. & FA2 & $20.54 \pm 0.23$ & $17.19 \pm 0.16$ \\
8. & FA3 & $18.15 \pm 0.15$ & $20.40 \pm 0.17$ \\
9. & FA4 & $21.20 \pm 0.17$ & $23.20 \pm 0.11$ \\
10. & FA5 & $17.80 \pm 0.14$ & $07.20 \pm 0.23$ \\
11. & FC1 & $09.80 \pm 0.16$ & 08.22 \\
12. & FC2 & $11.06 \pm 0.17$ & $08.21 \pm 0.15$ \\
13. & FC3 & $10.24 \pm 0.22$ & $11.10 \pm 0.20$ \\
14. & FC4 & $12.60 \pm 0.25$ & $11.50 \pm 0.14$ \\
15. & FC5 & $14.70 \pm 0.55$ & \\
\hline
\end{tabular}

$\mathrm{SD}^{*}$ : Standard deviation*, $\mathrm{n}=3$

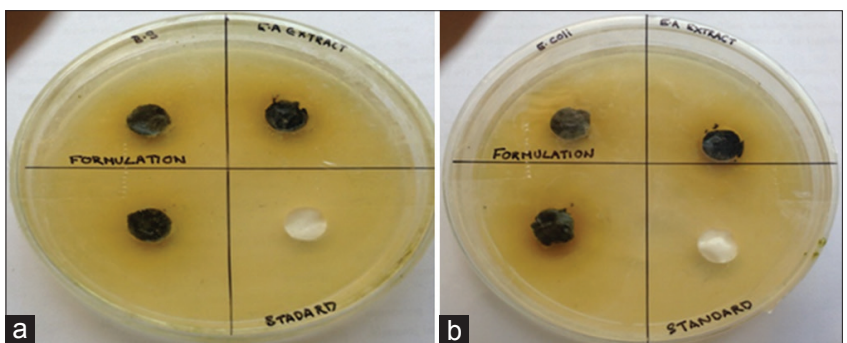

Fig. 1: Zone of inhibition shown by the ethyl acetate extract formulations for Escherichia coli (a) and Bacillus subtilis (b)

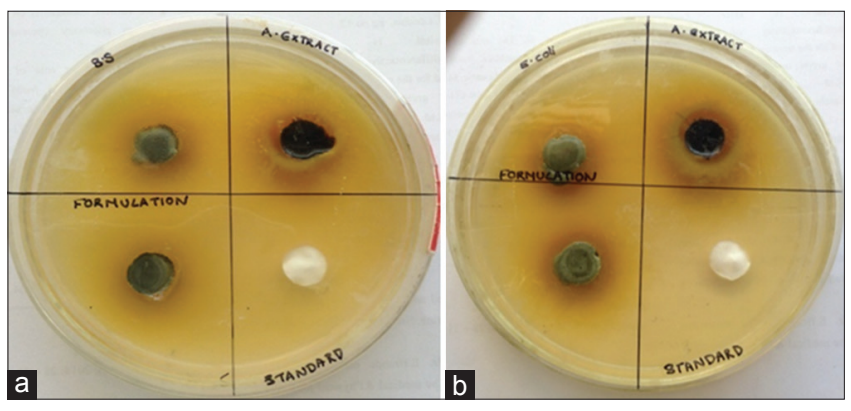

Fig. 2: Zone of inhibition shown by the alcohol extract formulations for Escherichia coli (a) and Bacillus subtilis (b)

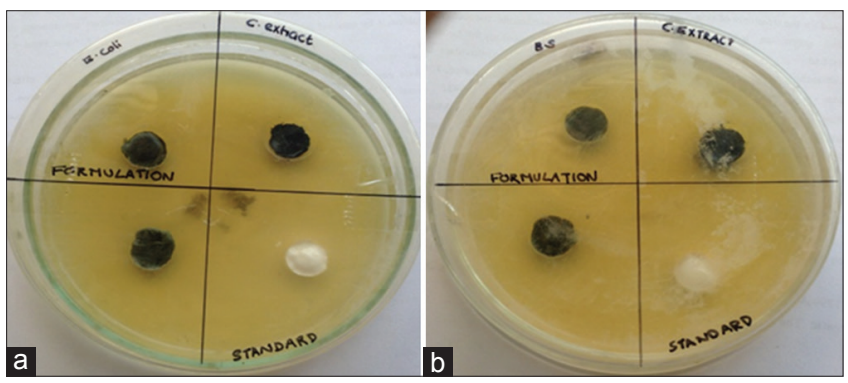

Fig. 3: Zone of inhibition shown by the chloroform extract formulations for Escherichia coli (a) and Bacillus subtilis (b)

separation studied at different time intervals such as $15,30,60$, and $90^{\text {th }}$ days [22-27]

\section{RESULTS AND DISCUSSION}

\section{Plant material extraction}

The yield of alcohol, ethyl acetate, and chloroform extract of aerial parts of E. glandulosum was found to be $19.32 \% \mathrm{w} / \mathrm{w}, 10.85 \% \mathrm{w} / \mathrm{w}$, and $7.24 \% \mathrm{w} / \mathrm{w}$, respectively, as shown in Table 4.

\section{Formulation of E. glandulosum ointments}

The ointment from E. glandulosum prepared using the fusion method. The prepared ointment filled into the tube and stored at room temperature. 
Table 7: Stability studies of ointments (FEA4, FA4, and FC5)

\begin{tabular}{llll}
\hline $\begin{array}{l}\text { Physicochemical } \\
\text { parameters }\end{array}$ & Formulations & \\
\cline { 2 - 3 } & FEA4 & FA4 & FC5 \\
\hline Color & Dark brown & Brown & Dark brown \\
Odor & Characteristic & Characteristic \\
Spreadability $+\mathrm{SD}^{*}$ & $5.1 \pm 0.51$ & $4.8 \pm 0.55$ & Characteristic \\
pH $+\mathrm{SD}^{*}$ & $7.10 \pm 0.24$ & $7.00 \pm 0.62$ & $5.0 \pm 0.23$ \\
Storage $\left(4^{\circ} \mathrm{C}, 24^{\circ} \mathrm{C}, 37^{\circ} \mathrm{C}\right)$ & Stable & Stable & $6.96 \pm 0.46$ \\
\hline
\end{tabular}

\section{Evaluation of $E$. glandulosum ointments}

The evaluation of ointments such as organoleptic parameters, homogeneity, spreadability, viscosity, $\mathrm{pH}$, and tube extrudability results is shown in Table 5.

\section{Antimicrobial study}

Prepared formulations have shown good activity against both B. subtilis and E. coli and it was found that the formulation of ethyl acetate-4, formulation of alcohol-4, and formulation of chloroform-5 (FEA4, FA4, and FC5) were showing more zone of inhibition comparing to all other formulations. The result of antimicrobial studies shown in Table 6 and the antimicrobial activity of all the extracts reported in Figs. 1-3.

\section{Stability studies}

The optimized formulations stability studies carried out at a different temperature and there is no marked change in the appearance of prepared ointments. The $\mathrm{pH}$ remains the same as the original $\mathrm{pH}$ of the ointments. The product is stable in the base of the ointment. The results are shown in Table 7.

Evaluations of the prepared ointments showed good results in spreadability, homogeneity, viscosity, tube extrudability, and antimicrobial activity and stable at different temperatures $\left(4^{\circ} \mathrm{C}, 25^{\circ} \mathrm{C}\right.$, and $37^{\circ} \mathrm{C}$ ). Based on these evaluation parameters and antimicrobial activity, it was found that the optimized formulations of FEA4, FA4, and FC5 were showing good results. When compared to these three formulations, FA4 showing more antimicrobial activity than the other two.

\section{CONCLUSION}

The study is concluded as the optimized formulations of different solvent extracts of E. glandulosum are efficient antimicrobial formulations and might be useful for related disorders. Further, isolation is required for the researchers to establish potential activities.

\section{AUTHORS' CONTRIBUTIONS}

We declare that this work was done by the authors named in this article Miss Silpa performed the experiment and collected the data; Hamsalakshmi helps in writing and designing the manuscript. Dr. J Suresh proofread the whole manuscript and suggested the necessary changes.

\section{CONFLICTS OF INTEREST}

The authors declare that there are no conflicts of interest regarding the publication of this paper.

\section{REFERENCES}

1. Liu S, Long Q, Xu Y, Wang J, Xu Z, Wang L, et al. Assessment of antimicrobial and wound healing effects of brevinin-2Ta against the bacterium Klebsiella pneumoniae in dermally-wounded rats. Oncotarget 2017;8:111369-85.

2. Shihabudeen HM, Priscilla DH, Thirumurugan K. Antimicrobial activity and phytochemical analysis of selected Indian folk medicinal plants. Int J Pharma Sci Res 2010;1:430-4.
3. Alavijeh PK, Alavijeh PK, Sharma D. A study of antimicrobial activity of few medicinal herbs. Asian J Plant Sci Res 2011;2:496-502.

4. Makinde AA, Igoli JO, TA'Ama L, Shaibu SJ, Garba A. Antimicrobial activity of Cassia alata. Afr J Biotechnol 2007;6:1509-10.

5. Parekha J, Chanda SV. Antibacterial activity of aqueous and alcoholic extracts of 34 Indian medicinal plants against some Staphylococcus species. Turk J Biol 2008;32:63-71.

6. Stary F, Hans S. The National Guides to Medical Herbs and Plants. UK: Tiger Books International; 1998.

7. Gislene GF, Locatelli J, Freitas PC, Silva GL. Antibacterial activity of plant extracts and phytochemicals on antibiotic resistant bacteria. Braz J Microbiol 2000;31:247-56.

8. Ashok GK. Introduction to Pharmaceutics-1, New Syllabus Implemented in the Year 1993, According to Regulation 1991. $3^{\text {rd }}$ ed. Chennai: CBS Publishers; 2006. p. 13.

9. Gaud RS, Dr. Yeole PG, Yadav AV, Gokhale SB. Textbook of Pharmaceutics. $10^{\text {th }}$ ed. Pune: Nirali Prakashan; 2008. p. 8.

10. Usha YS, Ashish AM. Review on: An ointment. Int J Pharmacogn Phytochem Res 2015;4:170-92.

11. Desingh M, Jesudas JM, Balasubramaniam P, Mayakrishnan P, Ganesan B, Mohan R. Phytochemical analysis and antimicrobial activity of Eupatorium glandulosum. Int J Curr Microbiol App Sci 2014;3:882-5

12. Iyeswarya MB, Manigundan K, Usha J, Devi PS, PriyaAS. Phytochemical study of methanolic leaf extract of Eupatorium glandulosum L. BioMedRx 2013;1:406-9.

13. Sasikumar JM, Doss AP, Doss A. Antibacterial activity of Eupatorium glandulosum leaves. Fitoterapia 2005;76:240-3.

14. Altoun ME. Altoun's Pharmaceutics the Design and Manufacture of Medicines. $3^{\text {rd }}$ ed. London: Elsevier, Churchill Livingstone; 2007. p. 593.

15. Chhetri HP, Yogol NS, Sherchan J, Anupa KC, Mansoor S, Panna Thapa Kathmandu. Uni J Sci 2010;6:102-7.

16. Chhetri HP, Yogol NS, Sherchan J, Anupa KC, Mansoor S, Thapa P. Formulation and evaluation of antimicrobial herbal ointment. Kathmandu Univ J Sci Eng Tech 2010;6:102-7.

17. Ravindra TJ, Pratibha RP, Payal HP. Formulation and evaluation of semisolid preparation (ointment, gel and cream) of thiocolchicoside. J Pharm Biomed Sci 2011;8:1-6.

18. Dey S, Mazuder B, Patel JR. Enhance percutaneous permeability of acyclovir by DMSO from topical gel formulation. Int J Pharm Sci Drug Res 2009;2:384-91.

19. Ketkomol P, Punjanon T. Comparative studies on physicochemical properties of Morinda citrifolia Gel and ointment formulations. Asian J Pharm Clin Res 2019;12:208-12.

20. Akanksha D, Vikas G, Neetesh KJ, Shailendra S, Neelam B, Dinesh KJ. Formulation and evaluation of neomycin sulphate ointment containing natural wound healing agent curcuma longa. Int J Pharm Sci Drug Res 2009; $1: 116-8$.

21. Rawat S, Singh R, Thakur P, Kaur S, Semwal A. Wound healing agents from medicinal plants: A review. Asian Pac J Trop Biomed 2012;2:1910-7.

22. Jyothi D, Koland M, Priya S. Investigation of anti-inflammatory activity of ointments containing fenugreek extract. Asian J Pharm Clin Res 2014;7:66-9.

23. Panda P, Ghosh A. Formulation and evaluation of topical dosage form of Eupatorium odoratum Linn. And their wound healing activity. Int $\mathrm{J}$ Pharma Bio Sci 2010;1:201-3.

24. Mohanta GP, Jamal M, Umdevi S. Formulation and evaluation of a polyherbal wound healing cream. Indian Drugs 2007;44:281-81.

25. Sumathi S, Banupriya SJ, Akhila V, Padma PR. Characterization, antimicrobial, and metabolic activity of green and chemically synthesized zinc oxide nanoparticles. Asian J Pharm Clin Res 
2019;12:11-7

26. Shinde AJ, Bhise SB, Jarag RJ, Jadhav NR. Preparation of cream containing Tridax procumbens, Curcuma longa and Azadirachta indica and its evaluation for wound healing property. Indian Pharm
2005;4:107-10.

27. Kamble P, Wadher S. Synthesis, in vitro antioxidant and antimicrobial evaluation of 3-hydroxy chromone derivatives. Asian J Pharm Clin Res 2018;1:259-68. 